\title{
Absorção de nutrientes em genótipos de girassol ${ }^{1}$
}

\author{
Debora Curado Jardini², Walcylene Lacerda Matos Pereira Scaramuzza ${ }^{2}$, \\ Oscarlina Lúcia Santos Weber ${ }^{2}$, Aluisio Brigido Borba Filho², Dayane Ávila Fernandes ${ }^{2}$
}

\begin{abstract}
Nutrient absorption in sunflower genotypes

Among the possibilities of obtaining high grain yields in a crop, as well as costs reduction, stands out the identification of genotypes with greater efficiency in the absorption and utilization of nutrients. This study aimed to evaluate agronomic traits (plant height, stem diameter and number of leaves), nutrient contents $(\mathrm{N}, \mathrm{P}, \mathrm{K}, \mathrm{Ca}, \mathrm{Mg}, \mathrm{S}$ and $\mathrm{B}$ ) and grain yield of sunflower genotypes. The experimental design was a randomized blocks design, with 8 genotypes (M734, HELIO 358, Embrapa 122, HLE 23, MG 341, BRS G37, BRS G41, V90631) and four replications. All genotypes presented plant height, stem diameter and number of leaves within the standards established for hybrids and commercial varieties. Foliar concentrations of $\mathrm{N}, \mathrm{P}, \mathrm{Mg}, \mathrm{S}$ and $\mathrm{B}$ were not influenced by the sunflower genotypes. The foliar contents of $\mathrm{K}$ and $\mathrm{Ca}$ were distinct among the sunflower genotypes, with the highest levels observed in HELIO 358 and MG341, respectively. The highest grain yields were obtained with BRS G37, HLE 23, M734 and HELIO 358 . There was a positive correlation between morphological characters and nutrient contents in the V90631 and Embrapa 122 cultivars, and between nutrient contents and grain yield in the M734 cultivar.
\end{abstract}

KEY-WORDS: Helianthus annus L.; genetic variability; macronutrients; boron.

\section{INTRODUÇÃO}

O girassol (Helianthus annuus L.) é uma oleaginosa extremamente adaptável a diferentes condições ambientais, por ser uma cultura tolerante à seca pouco influenciada pela altitude e latitude, com alto rendimento de grãos e de óleo, podendo contribuir significativamente para maior diversificação dos sistemas agrícolas (Leite et al. 2005).

Atualmente, é cultivada em várias partes, sendo a produção mundial de grãos de, aproxima-

\section{RESUMO}

Dentre as possibilidades de obtenção de elevados rendimentos de grãos, em uma cultura, bem como diminuição dos custos, destaca-se a identificação de genótipos com maior eficiência na absorção e utilização de nutrientes. Este trabalho objetivou avaliar caracteres agronômicos (altura de plantas, diâmetro de caule e número de folhas), teores de nutrientes (N, P, K, Ca, Mg, S e B) e rendimento de grãos de genótipos de girassol. O delineamento experimental utilizado foi o de blocos casualizados, com 8 genótipos (M734, HELIO 358, Embrapa 122, HLE 23, MG 341, BRS G37, BRS G41, V90631) e quatro repetições. Todos os genótipos apresentaram altura de plantas, diâmetro de caule e número de folhas dentro dos padrões estabelecidos para híbridos e variedades comerciais. Os teores foliares de N, P, Mg, S e B não foram influenciados pelos genótipos de girassol. Os teores foliares de $\mathrm{K}$ e Ca foram distintos entre os genótipos de girassol, sendo os maiores teores encontrados em HELIO 358 e MG341, respectivamente. Os maiores rendimentos de grãos foram obtidos com BRS G37, HLE 23, M734 e HELIO 358. Houve correlação positiva entre os caracteres morfológicos e teores de nutrientes, nas cultivares V90631 e Embrapa 122, e entre os teores de nutrientes e rendimento de grãos, na cultivar M734.

PALAVRAS-CHAVE: Helianthus annus L.; variabilidade genética; macronutrientes; boro.

damente, 39,1 milhões de toneladas (Brasil 2013). No Brasil, a cultura ainda tem pouca expressão, com cerca de 74,5 mil hectares cultivados na safra 2011/2012, sendo a maior concentração na região Centro-Oeste, com 66,0 mil hectares cultivados (Conab 2013). Porém, é uma cultura com excelentes perspectivas de expansão no Brasil, em decorrência das suas múltiplas funções, podendo ser utilizada para a produção de grãos, óleo, biocombustível, ração, silagem, adubação verde, planta de cobertura, ornamental e medicinal, bem como opção de cultivo

1. Trabalho recebido em nov./2013 e aceito para publicação em nov./2014 (nº registro: PAT 27269).

2. Universidade Federal de Mato Grosso (UFMT), Faculdade de Agronomia, Medicina Veterinária e Zootecnia, Cuiabá, MT, Brasil.E-mails: debora_jar@hotmail.com,wlmperei@yahoo.com.br, oscarlinaweber@gmail.com, borbafilho@terra.com.br, dayavila1@hotmail.com. 
de segunda safra ("safrinha"), tornado-se alternativa no sistema de rotação de culturas e proporcionando, assim, maior eficiência no uso da terra e beneficiando as culturas subsequentes (Sfredo et al. 1984, Oliveira et al. 2005, Vilalba 2008).

No entanto, sabe-se que o crescimento e desenvolvimento das culturas são condicionados por fatores genéticos e ambientais e suas interações. Entre os principais fatores ambientais, podem ser destacados o suprimento nutricional e o hídrico, como os mais importantes no desenvolvimento das culturas (Oliveira et al. 2010).

A cultura do girassol é exigente em fertilidade, absorvendo e acumulando grandes quantidades de nutrientes (Castro \& Oliveira 2005). Porém, sua resposta à adubação é limitada, sendo que grande parte desses nutrientes retorna ao solo, no momento da colheita, por meio da palhada (Vilalba 2008).

Além disso, a variabilidade de comportamento entre espécies vegetais, e mesmo entre genótipos, geralmente proporciona diferenças na capacidade de absorção de nutrientes (Oliveira et al. 2009). Logo, como a exigência entre cultivares da mesma espécie é distinta, é comum observar acúmulo diferenciado de nutrientes e fitomassa, assim como variações de caracteres agronômicos (altura de plantas, diâmetro de caule, número de folhas, etc.), sob as mesmas condições de cultivo e para o mesmo ano agrícola (Fageria 1989, Castro \& Farias 2005). Portanto, quando se objetiva alcançar elevados rendimentos de grãos, em uma cultura, uma das possibilidades é selecionar genótipos com maior eficiência nutricional, ou seja, plantas com maior eficiência na absorção e utilização de nutrientes (Abichequer 2004).

Diversos fatores influenciam na absorção e disponibilidade de nutrientes do solo, ou seja, a capacidade de exploração do sistema radicular da planta, propriedades do solo e seu manejo, condições climáticas e disponibilidade de água são aspectos fundamentais para se obter uma planta bem nutrida (Fageria 1998, Vilalba 2008, Zobiole et al. 2011). Logo, a otimização desses fatores é essencial para elevar a eficiência produtiva da cultura. Além disso, parte do sucesso da cultura do girassol, no Brasil, está associado à escolha adequada de cultivares com adaptação a diferentes ambientes, justificando, assim, estudos de cultivares de girassol.

Diante disso, torna-se necessária a avaliação e o conhecimento dos teores de nutrientes nas folhas de cada genótipo, no intuito de conhecer a capacidade produtiva de cada um deles e melhorar o manejo da adubação da cultura.

Aquino et al. (2013), avaliando o estado nutricional, caracteres agronômicos e produtividade de dez cultivares de girassol sob irrigação, no norte de Minas Gerais, observaram que os teores foliares de nutrientes não afetaram o rendimento de grãos das cultivares avaliadas. Portanto, avaliações nutricionais podem contribuir para indicar os teores foliares adequados, de acordo com o rendimento da cultura.

Assim, o presente trabalho objetivou avaliar caracteres agronômicos, bem como quantificar os teores dos nutrientes nitrogênio, fósforo, potássio, cálcio, magnésio, enxofre e boro, na folha de genótipos de girassol, e sua relação com o rendimento da cultura.

\section{MATERIAL E MÉTODOS}

O experimento faz parte da Rede de Ensaio de Avaliação de Genótipos da Embrapa, realizado na área experimental do Instituto Federal de Educação, Ciência e Tecnologia de Mato Grosso (IFMT), localizado na Vila de São Vicente da Serra, município de

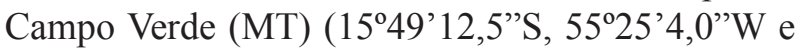
altitude de $772 \mathrm{~m}$ ), na safra 2013/2014. O clima da área é classificado, segundo Köppen, como do tipo transição Cwa-(Cwb), com temperatura média anual de $23,4^{\circ} \mathrm{C}$ e precipitação pluviométrica média anual de $1.978 \mathrm{~mm}$. Na Figura 1, encontram-se os dados de temperatura e precipitação pluviométrica registrados durante o período do experimento.

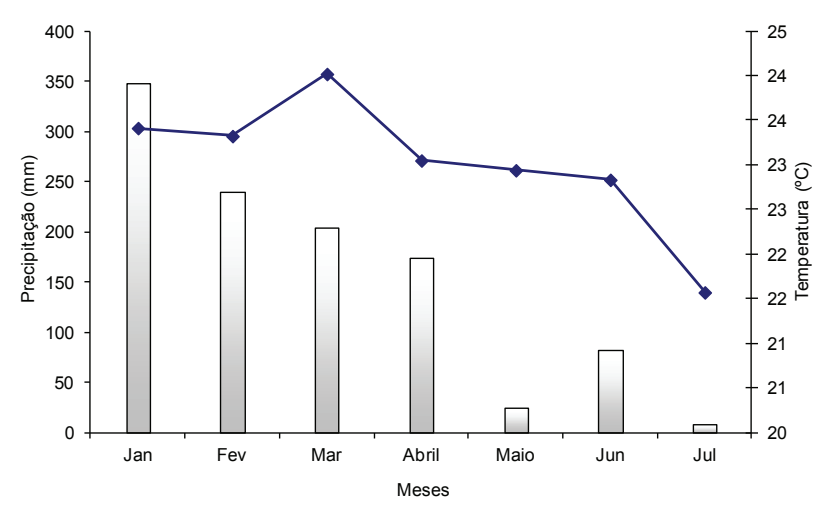

Figura 1. Temperatura $\left({ }^{\circ} \mathrm{C}\right)$ e precipitação pluviométrica $(\mathrm{mm})$ durante o período de condução do experimento (Campo Verde, MT, 2013). Fonte: Estação Meteorológica do IFMT. 
O solo da área experimental foi classificado como Latossolo Vermelho distrófico (LVd) de textura argilosa (Embrapa 2006). Para a caracterização química e granulométrica (Tabela 1), à profundidade de 0-20 m, seguiu-se metodologia da Embrapa (1997).

O preparo do solo consistiu de uma aração, seguida de uma gradagem, para destorroar e nivelar o solo, na camada de $0-20 \mathrm{~cm}$. Na semeadura, foram distribuídos e incorporados ao sulco $570 \mathrm{~kg} \mathrm{ha}^{-1}$ do formulado 4-14-8 e $2 \mathrm{~kg} \mathrm{ha}^{-1}$ de boro, na forma de borogran (11\% de boro). A adubação de cobertura foi realizada trinta dias após a emergência das plantas, sendo aplicados $87 \mathrm{~kg} \mathrm{ha}^{-1}$ de ureia e $57 \mathrm{~kg} \mathrm{ha}^{-1}$ de $\mathrm{KCl}$. A adubação, tanto de semeadura quanto de cobertura, foi efetuada em função da expectativa de rendimento de grãos $\left(4 \mathrm{t} \mathrm{ha}^{-1}\right)$ (Souza \& Lobato 2004).

O delineamento experimental foi em blocos ao acaso, com oito tratamentos e quatro repetições. Os tratamentos consistiram dos genótipos Embrapa 122, M734, HELIO 358, HLE 23, MG 341, BRS G37, BRS G41 e V90631. Todos esses genótipos são cultivados e recomendados para a região do Cerrado.

Foi realizado semeio de três sementes por cova e, quinze dias após a emergência das plantas, efetuado o desbaste, deixando-se apenas uma planta por cova. Cada unidade experimental foi constituída de quatro fileiras de 6,0 m de comprimento, com espaçamento entre as linhas de $0,90 \mathrm{~m}$ e de $0,25 \mathrm{~m}$ entre as plantas. Para efeito de coleta de dados, foram consideradas apenas as duas linhas centrais, eliminando-se $0,5 \mathrm{~m}$ nas extremidades das fileiras, sendo a área útil de $9,0 \mathrm{~m}^{2}$. Os tratos culturais referentes a pragas e doenças foram realizados de acordo com os monitoramentos e recomendações agronômicas da Embrapa. O controle de plantas daninhas foi realizado por meio de capina manual, utilizando-se enxada. Além disso, antes da maturação fisiológica, os capítulos da área útil foram ensacados com sacos brancos, para protegê-los do ataque de pássaros.
Quando 50\% das plantas da área útil estavam em R3 (segunda fase do alongamento do botão floral, ou seja, o botão encontra-se $2,0 \mathrm{~cm}$ acima da última folha), determinou-se a altura de 10 plantas ao acaso, tomando-se como medida a distância do solo até a inserção da inflorescência, com o auxílio de uma fita métrica, ocasião em que as folhas totalmente expandidas das referidas plantas foram contabilizadas. Avaliou-se, também, o diâmetro de caule, medido com paquímetro digital, a 5,0 cm do nível do solo.

Em cada cultivar, coletou-se a folha índice completamente expandida a partir do ápice (sexta folha no sentido da inflorescência para baixo) (Amabile et al. 2009). As folhas foram lavadas com água deionizada e, em seguida, colocadas em estufa com ventilação forçada de ar, a $70^{\circ} \mathrm{C}$, até atingirem massa constante. Após a secagem, procedeu-se à trituração em moinho do tipo Willey e, posteriormente, à pesagem e quantificação dos teores de $\mathrm{N}, \mathrm{P}, \mathrm{K}, \mathrm{Ca}$, $\mathrm{Mg}$, S e B (Malavolta et al. 1997). Quando as plantas encontravam-se no estádio de maturação fisiológica (R9), com cerca de $14 \%$ de umidade, foi realizada a colheita manual dos capítulos e, em seguida, trilhados, e os aquênios (sementes) foram limpos e secos ao sol e, posteriormente, pesados e avaliados quando à umidade. O rendimento de grãos foi obtido pela massa da parcela da área útil, corrigindo-se para umidade padrão de $11 \%$, extrapolado para $\mathrm{kg} \mathrm{ha}^{-1}$.

Os dados foram analisados estatisticamente por meio da análise de variância e pelo teste F. Nos casos de significância $(p<0,05)$, foi realizado o teste de média Scott-Knott, a 5\%. Os dados também foram submetidos à análise do coeficiente de correlação de Pearson, a $5 \%$ e $1 \%$.

\section{RESULTADOS E DISCUSSÃO}

De acordo com o teste de Scott Knott a 5\% (Tabela 2), verificou-se que não houve diferença entre os genótipos, em relação aos aspectos morfológicos

Tabela 1. Atributos químicos e granulométricos do Latossolo Vermelho distrófico (LVd) de textura argilosa da área experimental, à profundidade 0-20 cm (Campo Verde, MT, 2013).

\begin{tabular}{|c|c|c|c|c|c|c|c|c|c|c|c|}
\hline \multicolumn{2}{|c|}{$-\mathrm{pH}-$} & $\mathrm{P}$ & $\mathrm{K}$ & $\mathrm{K}$ & $\mathrm{Ca}+\mathrm{Mg}$ & $\mathrm{Ca}$ & $\mathrm{Mg}$ & $\mathrm{Al}$ & $\mathrm{H}$ & $\mathrm{H}+\mathrm{Al}$ & \multirow{2}{*}{$\frac{\mathrm{MO}}{\mathrm{g} \mathrm{dm}^{-3}}$} \\
\hline Água & $\mathrm{CaCl}_{2}$ & \multicolumn{2}{|c|}{$-\mathrm{mg} \mathrm{dm}^{-3}$} & \multicolumn{7}{|c|}{$\mathrm{cmol} \mathrm{dm}^{-3}$} & \\
\hline 5,90 & 5,00 & 3,00 & 60,20 & 0,15 & 2,85 & 2,13 & 0,72 & 0,00 & 2,81 & 2,81 & 20,00 \\
\hline SB & $\mathrm{T}$ & $\mathrm{V}$ & $\mathrm{Zn}$ & $\mathrm{Cu}$ & $\mathrm{Fe}$ & $\mathrm{Mn}$ & B & $\mathrm{S}$ & Areia & Silte & Argila \\
\hline \multicolumn{2}{|c|}{$-\mathrm{cmol} \mathrm{dm}^{-3}$} & $\%$ & & & $-\mathrm{mg}$ & & & & & $\mathrm{g} \mathrm{kg}^{-1}$ & \\
\hline 3,00 & 5,80 & 51,70 & 15,90 & 6,00 & 85,70 & 6,60 & 0,33 & 7,10 & 460,00 & 114,00 & 426,00 \\
\hline
\end{tabular}


Tabela 2. Aspectos morfológicos dos genótipos de girassol, no início do florescimento (Campo Verde, MT, safra 2013/2014).

\begin{tabular}{lccc}
\hline Genótipo & Altura $(\mathrm{m})$ & Diâmetro $(\mathrm{cm})$ & $\mathrm{N}^{\mathrm{o}}$ de folhas \\
\hline M734 & $0,99 \mathrm{a}$ & $2,21 \mathrm{a}$ & $20 \mathrm{~b}$ \\
Helio 358 & $0,92 \mathrm{a}$ & $2,05 \mathrm{a}$ & $22 \mathrm{~b}$ \\
Embrapa 122 & $1,02 \mathrm{a}$ & $2,06 \mathrm{a}$ & $25 \mathrm{a}$ \\
HLE 23 & $0,92 \mathrm{a}$ & $2,00 \mathrm{a}$ & $24 \mathrm{a}$ \\
MG 341 & $0,95 \mathrm{a}$ & $2,13 \mathrm{a}$ & $22 \mathrm{~b}$ \\
BRS G37 & $0,97 \mathrm{a}$ & $2,34 \mathrm{a}$ & $21 \mathrm{~b}$ \\
BRS G41 & $1,03 \mathrm{a}$ & $2,28 \mathrm{a}$ & $22 \mathrm{~b}$ \\
V90631 & $1,07 \mathrm{a}$ & $2,28 \mathrm{a}$ & $24 \mathrm{a}$ \\
\hline Média & 0,98 & 2,17 & 23 \\
\hline CV\% & 7,52 & 8,48 & 6,32 \\
\hline
\end{tabular}

Médias seguidas pela mesma letra não diferem entre si, pelo Teste de Scott-Knott a $5 \%$.

(altura de planta e diâmetro de caule). A altura dos genótipos variou de 0,92 m (híbrido HLE 23) a $1,07 \mathrm{~m}$ (híbrido V90631). Porém, todos os genótipos avaliados tiveram altura de planta dentro dos valores considerados padrões para híbridos e variedades comerciais, que são de 0,7-4,0 m (Castro \& Farias 2005).

Carvalho et al. (2005) relatam que plantas altas de girassol são desejáveis em ambientes com baixo controle de doenças ou solos com baixo nível de fertilidade, e plantas baixas, além de facilitarem a colheita, são desejáveis quando existem problemas de acamamento. Segundo Ivanoff (2009), a altura das plantas é reflexo das condições nutricionais, no período de alongamento do caule.

$\mathrm{O}$ diâmetro de caule variou de $2 \mathrm{~cm}$ (híbrido HLE 23) a 2,34 cm (híbrido BRS G37). Porém, todos os genótipos avaliados apresentaram diâmetro de caule dentro dos valores considerados padrões, para híbridos e variedades comerciais, que são de $1-8 \mathrm{~cm}$ (Castro \& Farias 2005). O diâmetro de caule também é uma característica importante para a cultura, pois seu bom desenvolvimento permite que ocorra menos acamamento, facilitando seu manejo, tratos e colheita (Biscaro et al. 2008, Alves et al. 2010). Além da altura de plantas, o acamamento está relacionado com o diâmetro de caule (Carvalho et al. 2005). Por isso, caules grossos propiciam plantas fortes e resistentes, capazes de sustentar a produção de capítulos, reduzindo os riscos de quebra ou acamamento (Castro \& Farias 2005).

Em relação ao número de folhas por planta, os genótipos Embrapa 122, HLE 23 e V90631 tiveram maior número de folhas, em relação aos demais ge- nótipos. De modo geral, todos os genótipos avaliados tiveram número de folhas adequado, que, segundo Castro \& Farias (2005), pode variar de 20 a 40 folhas por planta. Carvalho et al. (2005) relatam que o número de folhas é influenciado tanto por fatores genéticos como por fatores ambientais. A folha é o principal aparato fotossintético, acumulando, além de nutrientes, compostos orgânicos que serão posteriormente translocados para os órgãos reprodutivos e os grãos (Castro \& Farias 2005). Portanto, o número de folhas torna-se decisivo para obter uma produção maior de aquênios, por manter relação direta com o estado nutricional da planta (Biscaro et al. 2008, Ivanoff 2009, Zobiole et al. 2010).

$\mathrm{O}$ teor de $\mathrm{N}$ foliar não diferiu entre os genótipos (Tabela 3), variando em 30,52-37,38 $\mathrm{g} \mathrm{kg}^{-1}$. No entanto, o genótipo V90631 foi o único que apresentou teor de $\mathrm{N}$ considerado adequado por Castro \& Oliveira (2005), que é de $35-50 \mathrm{~g} \mathrm{~kg}^{-1}$. O baixo teor de $\mathrm{N}$ nas folhas pode ocasionar redução no desenvolvimento das plantas, afetando o número de folhas, altura de plantas, diâmetro de caule, área foliar (Prado \& Leal 2006), produção de grãos e teor de óleo e proteína na cultura (Sanzonowicz \& Amabile 2001).

$\mathrm{O}$ teor de $\mathrm{P}$ foliar não diferiu entre os genótipos, variando em 1,09-1,03 $\mathrm{g} \mathrm{kg}^{-1}$ (Tabela 3). Porém, todos os genótipos avaliados tiveram teor de $\mathrm{P}$ considerado baixo $\left(<2,9 \mathrm{~g} \mathrm{~kg}^{-1}\right)$, segundo Castro \& Oliveira (2005). O baixo teor de P foliar pode estar relacionado à baixa concentração desse nutriente no solo (3,0 $\left.\mathrm{mg} \mathrm{kg}^{-1}\right)$ (Tabela 1). Isso também pode estar relacionado à baixa mobilidade desse elemento no solo, onde o contato do íon fosfato com as raízes geralmente acontece pelo processo de difusão, razão pela qual a absorção do nutriente depende do volume de solo explorado pela cultura, umidade do solo e, também, textura do solo, que apresenta grande capacidade de adsorção e precipitação de $\mathrm{P}$, limitando a disponibilidade para as plantas (Aguiar Neto et al. 2010).

Houve diferença no teor de $\mathrm{K}$ foliar, sendo que o genótipo Helio 358 apresentou maior teor de $\mathrm{K}$, quando comparado com os outros genótipos (Tabela 3). Além disso, o genótipo Helio 358 foi o único que apresentou teor de $\mathrm{K}$ considerado adequado (31,0 $\left.\mathrm{g} \mathrm{kg}^{-1}\right)$, segundo Castro \& Oliveira (2005), que é de 31-45 $\mathrm{g} \mathrm{kg}^{-1}$. De acordo com Castro et al. (2006), o genótipo Helio 358 apresenta elevada capacidade de exploração do solo e absorção de potássio, o que 
favorece positivamente a produção de aquênios, na cultura do girassol. Os resultados obtidos neste estudo permitem inferir que o genótipo Helio 358 apresentou maior eficiência na utilização de $\mathrm{K}$, tanto do solo como o incorporado por meio do adubo $\mathrm{KCl}$, em detrimento dos demais materiais genéticos, uma vez que os teores de $\mathrm{K}$ no solo da área experimental estavam baixos e os demais genótipos não tiveram a mesma capacidade de absorver e acumular K nas folhas.

Entretanto, de acordo com a análise de solo da Tabela 1, os teores de K no solo da área experimental estavam baixos $\left(0,15 \mathrm{cmol}_{\mathrm{c}} \mathrm{dm}^{-3}\right)$, pois, segundo Blamey et al. (1987), o teor de potássio disponível no solo, para atender o requerimento da planta, deve ser superior a $0,25 \mathrm{cmol}_{\mathrm{c}} \mathrm{dm}^{-3}$. Além disso, Borkert et al. (1997) relatam que menos de $0,12 \mathrm{cmol}_{\mathrm{c}} \mathrm{dm}^{-3}$ de K disponível mantém baixa a sua absorção, assim como o seu teor na folha, limitando o rendimento da cultura.

$\mathrm{O}$ teor de $\mathrm{Ca}$ diferiu entre os genótipos (Tabela 3), sendo que os genótipos BRS G37 e V90631 apresentaram menor teor de Ca foliar $(6,50$ e 7,50, respectivamente). No entanto, todos os genótipos apresentaram teor de $\mathrm{Ca}$ foliar baixo, segundo Castro \& Oliveira (2005). Para os mesmos autores, a faixa de concentração considerada suficiente às plantas de girassol é de 19-32 $\mathrm{g} \mathrm{kg}^{-1}$. Porém, o baixo teor de Ca nas folhas dos genótipos não foi suficiente para afetar a produtividade, ou causar qualquer sintoma visual de deficiência nas plantas.

Não houve diferença entre os genótipos, em relação ao teor de $\mathrm{Mg}$ foliar, variando em 11,85$14,70 \mathrm{~g} \mathrm{~kg}^{-1}$ (Tabela 3). Porém, todos os genótipos apresentaram teores de $\mathrm{Mg}$ foliar considerados altos por Castro \& Oliveira (2005), ou seja, superiores a $9,4 \mathrm{~g} \mathrm{~kg}^{-1}$. Os teores de $\mathrm{S}$ foliar não diferiram entre os genótipos, variando em 7,19-9,46 g kg-1 (Tabela 3), teores considerados altos, segundo Castro \& Oliveira (2005), ou seja, superiores a $6,4 \mathrm{~g} \mathrm{~kg}^{-1}$. Isso pode estar relacionado ao alto nível desse elemento presente no solo (Tabela 1) e, também, ao fato de seu processo de contato com as raízes ser realizado, principalmente, por fluxo de massa. De maneira geral, os teores elevados de $\mathrm{Mg}$ e $\mathrm{S}$ nas folhas dos genótipos não ocasionaram nenhum sintoma visual de toxicidade nas plantas.

Não houve diferença entre os genótipos, em relação ao teor de B foliar (Tabela 3). No entanto, os teores de boro foliar mostraram-se abaixo do nível considerado adequado por Castro \& Oliveira (2005), que é de $35-80 \mathrm{mg} \mathrm{kg}^{-1}$. Os baixos teores foliares de $\mathrm{B}$ nos genótipos podem estar relacionados ao baixo teor desse nutriente no solo $\left(0,33 \mathrm{mg} \mathrm{dm}^{-3}\right)$. Isso pode estar associado com a adsorção do B à argila, pois, segundo Gutterres (1986), o teor de B diminui em solos argilosos, devido à maior área específica da argila, aumentando a adsorção do nutriente. Além disso, o pH da solução do solo também pode estar favorecendo a adsorção do nutriente, pois, segundo estudo realizado por Soares et al. (2008), a adsorção de $\mathrm{B}$ tende a aumentar, em função de $\mathrm{pH}$ no intervalo entre 3 e 9.

Baixos teores foliares de $\mathrm{B}$ podem ocasionar crescimento reduzido de folhas jovens e, no caule, podem provocar pequenos cortes logo abaixo da inserção dos capítulos, podendo propiciar a sua queda. Nos capítulos, podem acarretar redução de tamanho, deformação e até mesmo a sua queda (Castro \& Oliveira 2005).

Houve diferença no rendimento de grãos entre os genótipos avaliados, sendo que o maior

Tabela 3. Teores de nutrientes dos genótipos de girassol, no início do florescimento (Campo Verde, MT, safra 2013/2014).

\begin{tabular}{lccrrrcc}
\hline \multicolumn{1}{c}{ Genótipo } & Nitrogênio & Fósforo & Potássio & Cálcio & Magnésio & Enxofre & Boro \\
\hline M734 & & & $\mathrm{g} \mathrm{kg}^{-1}$ & & & & $\mathrm{mg} \mathrm{kg}^{-1}$ \\
\hline Helio 358 & $32,34 \mathrm{a}$ & $1,07 \mathrm{a}$ & $27,50 \mathrm{~b}$ & $10,25 \mathrm{a}$ & $14,55 \mathrm{a}$ & $8,14 \mathrm{a}$ & $13,57 \mathrm{a}$ \\
Embrapa 122 & $34,30 \mathrm{a}$ & $1,05 \mathrm{a}$ & $31,00 \mathrm{a}$ & $9,25 \mathrm{a}$ & $14,70 \mathrm{a}$ & $8,15 \mathrm{a}$ & $18,37 \mathrm{a}$ \\
HLE 23 & $33,88 \mathrm{a}$ & $1,09 \mathrm{a}$ & $24,00 \mathrm{c}$ & $10,75 \mathrm{a}$ & $12,15 \mathrm{a}$ & $8,18 \mathrm{a}$ & $16,35 \mathrm{a}$ \\
MG 341 & $33,74 \mathrm{a}$ & $1,06 \mathrm{a}$ & $25,50 \mathrm{c}$ & $9,00 \mathrm{a}$ & $11,85 \mathrm{a}$ & $7,19 \mathrm{a}$ & $12,27 \mathrm{a}$ \\
BRS G37 & $30,52 \mathrm{a}$ & $1,06 \mathrm{a}$ & $23,50 \mathrm{c}$ & $11,75 \mathrm{a}$ & $13,65 \mathrm{a}$ & $7,79 \mathrm{a}$ & $18,21 \mathrm{a}$ \\
BRS G41 & $27,02 \mathrm{a}$ & $1,06 \mathrm{a}$ & $22,50 \mathrm{c}$ & $6,50 \mathrm{~b}$ & $12,75 \mathrm{a}$ & $7,64 \mathrm{a}$ & $17,30 \mathrm{a}$ \\
V90631 & $31,78 \mathrm{a}$ & $1,04 \mathrm{a}$ & $28,50 \mathrm{~b}$ & $9,00 \mathrm{a}$ & $12,60 \mathrm{a}$ & $8,46 \mathrm{a}$ & $11,74 \mathrm{a}$ \\
\hline Média & $37,38 \mathrm{a}$ & $1,03 \mathrm{a}$ & $25,00 \mathrm{c}$ & $7,50 \mathrm{~b}$ & $13,05 \mathrm{a}$ & $9,46 \mathrm{a}$ & $14,40 \mathrm{a}$ \\
\hline CV\% & 32,62 & 1,06 & 25,93 & 9,25 & 13,16 & 8,13 & 15,28 \\
\hline Médias seguidas pela mesma letra não diferem entre si, pelo Teste de Scott-Knott a $5 \%$. & & & 13,74 & 14,79 & 27,02 \\
\hline
\end{tabular}


rendimento foi obtido para os genótipos BRS G37 $\left(2.462 \mathrm{~kg} \mathrm{ha}^{-1}\right)$, HLE $23\left(2.437 \mathrm{~kg} \mathrm{ha}^{-1}\right)$, M734 $\left(2.355 \mathrm{~kg} \mathrm{ha}^{-1}\right)$ e Helio 358 (2.046 kg ha-1) (Tabela 4). A média obtida entre os oitos genótipos, para essa característica agronômica, foi de $1.886 \mathrm{~kg} \mathrm{ha}^{-1}$, discordando dos resultados encontrados por Carvalho et al. (2013), em ensaio final do primeiro ano safrinha, realizado em Planaltina (DF), no Centro de Pesquisa Agropecuária dos Cerrados (Embrapa Cerrados), onde foi obtido rendimento médio de grãos de $3.515 \mathrm{~kg} \mathrm{ha}^{-1}$, para os mesmos genótipos avaliados neste trabalho. Isso pode estar relacionado às condições climáticas favoráveis ao cultivo do girassol e à disponibilidade hídrica na região, em relação às do presente trabalho (Figura 1).

A baixa precipitação pluviométrica, principalmente no início do florescimento, pode ter prejudicado a absorção de nutrientes pelas plantas, refletindo, consequentemente, no rendimento de grãos da cultura. Entretanto, quando comparado com a média nacional obtida na safra 2011/2012 (1.494 $\left.\mathrm{kg} \mathrm{ha}^{-1}\right)$, nota-se que as médias obtidas para os oito genótipos avaliados superaram a média nacional, bem como a média da região Centro-Oeste (1.512 $\left.\mathrm{kg} \mathrm{ha}^{-1}\right)$ e do Estado de Mato Grosso (1.500 kg ha-1) (Brasil 2013).

De maneira geral, todos os genótipos avaliados tiveram rendimento de grãos adequado à região do Cerrado, mesmo contendo teores foliares de nutrientes considerados abaixo do adequado para a cultura, para a maioria dos nutrientes avaliados.

A altura de plantas apresentou correlação positiva com o diâmetro de caule, para os genótipos Embrapa 122, M734, BRS G37 e BRS G41, sendo a maior correlação encontrada para o genótipo BRS

Tabela 4. Rendimento de grãos de genótipos de girassol (Campo Verde, MT, safra 2013/2014).

\begin{tabular}{lc}
\hline \multicolumn{1}{c}{ Genótipo } & Rendimento $\left(\mathrm{kg} \mathrm{ha}^{-1}\right)$ \\
\hline M734 & $2.355 \mathrm{a}$ \\
Helio 358 & $2.046 \mathrm{a}$ \\
Embrapa 122 & $1.650 \mathrm{~b}$ \\
HLE 23 & $2.437 \mathrm{a}$ \\
MG 341 & $1.347 \mathrm{~b}$ \\
BRS G37 & $2.462 \mathrm{a}$ \\
BRS G41 & $1.231 \mathrm{~b}$ \\
V90631 & $1.560 \mathrm{~b}$ \\
\hline Média & 1.886 \\
\hline CV\% & 17.960 \\
\hline Médias seguidas pela mesma letra não diferem entre si, pelo Teste de Scott-Knott \\
a 5\%.
\end{tabular}

G37 (Tabela 5). A correlação foi positiva entre a altura de plantas e o número de folhas, para os genótipos Embrapa 122, HLE 23 e V90631. Do mesmo modo, foi observada correlação positiva entre diâmetro de caule e número de folhas, para os genótipos Embrapa 122 e V90631. Resultado semelhante foi constatado por Amorim et al. (2008), que verificaram correlação significativa e positiva entre diâmetro de haste e altura de plantas $(\mathrm{r}=0,84)$, número de folhas e altura de plantas $(\mathrm{r}=0,58)$ e diâmetro de caule e número de folhas $(r=0,73)$, para os 14 genótipos de girassol avaliados.

Em relação aos teores de nutrientes foliares e aspectos morfológicos avaliados, houve correlação positiva entre o teor de $\mathrm{N}$ foliar e o diâmetro de caule, para o genótipo V90631 (Tabela 6). Santos et al. (2013), trabalhando com doses de N, verificaram que o diâmetro de caule aumentou conforme aumentaram as doses de N. Segundo os mesmos autores, o N é o elemento responsável pelo crescimento geral das plantas de girassol, sendo, também, responsável pelos maiores diâmetros da haste do girassol. Prado \& Leal (2006) ressaltaram que a omissão de $\mathrm{N}$ reduz significativamente o diâmetro de caule das plantas de girassol.

Tabela 5. Estimativas de coeficientes de correlação entre os aspectos morfológicos dos genótipos de girassol avaliados (Campo Verde, MT, safra 2013/2014).

\begin{tabular}{llll}
\hline \multirow{2}{*}{ Genótipo } & \multicolumn{3}{c}{ Correlação } \\
\cline { 2 - 4 } & ALT-DC & ALT-NF & DC-NF \\
\hline Embrapa 122 & $0,9790^{*}$ & $0,9538^{*}$ & $0,9568^{*}$ \\
M734 & $0,9685^{*}$ & & \\
BRS G37 & $0,9942 * *$ & & \\
BRS G41 & $0,9892^{*}$ & & \\
HLE 23 & & $0,9716^{*}$ & \\
V90631 & & $0,9969 * *$ & $0,9517 *$ \\
\hline * significativo a 5\%, pelo Teste t; ** significativo a $1 \%$, pelo Teste t. ALT $=$ altura
\end{tabular}

* significativo a $5 \%$, pelo Teste $\mathrm{t}$; ** significativo a $1 \%$, pelo Teste $\mathrm{t}$. ALT $=$ altura de plantas; $\mathrm{DC}=$ diâmetro de caule; $\mathrm{NF}=$ número de folhas.

Tabela 6. Estimativas de coeficientes de correlação entre os teores de nutrientes foliares e os aspectos agronômicos dos genótipos de girassol avaliados (Campo Verde, MT, safra 2013/2014).

\begin{tabular}{lccc}
\hline \multirow{2}{*}{ Genótipo } & \multicolumn{3}{c}{ Correlação } \\
\cline { 2 - 4 } & N-DC & K-ALT & K-NF \\
\hline V90631 & $0,9578^{*}$ & & \\
Embrapa 122 & & $0,9558^{*}$ & $0,9865^{*}$ \\
\hline
\end{tabular}

* significativo a $5 \%$, pelo Teste t. $\mathrm{N}=$ nitrogênio foliar; $\mathrm{DC}=$ diâmetro de caule; $\mathrm{K}=$ potássio foliar; $\mathrm{ALT}=$ altura de plantas; $\mathrm{NF}=$ número de folhas. 
Observou-se correlação positiva entre o teor de $\mathrm{K}$ foliar e altura de plantas e número de folhas, para o genótipo Embrapa 122 (Tabela 6). Ivanoff (2009) observou que a adubação potássica favorece a altura, em plantas de girassol. Jesus et al. (2013), trabalhando com doses de K, observaram que a altura de plantas, assim como o número de folhas, aumentaram conforme a elevação das doses de K. Segundo Cecílio Filho \& Grangeiro (2004), no caso de deficiência de potássio, ocorre funcionamento irregular dos estômatos, podendo diminuir a assimilação de $\mathrm{CO}_{2}$ e a taxa fotossintética, afetando, negativamente, o crescimento vegetativo e, consequentemente, a produção das plantas.

Em relação aos teores de nutrientes foliares e rendimento de grãos, verificou-se correlação positiva para o teor de $\mathrm{K}$ foliar e o rendimento de grãos, para o genótipo M734 (Tabela 7). Segundo Blamey et al. (1997), produtividades máximas de girassol somente são obtidas com teores superiores a 24,0 $\mathrm{g} \mathrm{kg}^{-1}$ de K nas folhas. Borkert et al. (1997) obtiveram teores de $12,8 \mathrm{~g} \mathrm{~kg}^{-1}, 18,8 \mathrm{~g} \mathrm{~kg}^{-1}$ e $27,0 \mathrm{~g} \mathrm{~kg}^{-1}$ de $\mathrm{K}$ nas folhas e produções de $1.409 \mathrm{~kg} \mathrm{ha}^{-1}, 2.032 \mathrm{~kg} \mathrm{ha}^{-1}$ e $1.986 \mathrm{~kg} \mathrm{ha}^{-1}$, respectivamente, demonstrando que, não havendo falta desse nutriente, o rendimento do girassol pode atingir $2.000 \mathrm{~kg} \mathrm{ha}^{-1}$, ou mais, podendo ser considerado bom esse rendimento em uma lavoura.

De maneira geral, todos os genótipos avaliados apresentaram aspectos morfológicos e rendimento de grãos considerados satisfatórios para o cultivo em Campo Verde, mesmo contendo teores foliares de nutrientes divergentes dos recomendados para a cultura, no início do florescimento. Além disso, nenhum sintoma de deficiência e/ou toxidade foi observado nos genótipos, em decorrência desses baixos e altos teores de nutrientes. Portanto, todos os genótipos podem ser recomendados e utilizados na região do Cerrado.

Tabela 7. Estimativas de coeficientes de correlação entre os teores de nutrientes foliares e o rendimento de grãos dos genótipos de girassol avaliados (Campo Verde, MT, safra 2013/2014).

\begin{tabular}{lc}
\hline Genótipo & Correlação \\
\cline { 2 - 2 } M734 & K-REND \\
\hline $\begin{array}{l}\text { * significativo a } 5 \% \text {, pelo Teste t. } \mathrm{K} \text { = potássio foliar; } \text { REND }=\text { rendimento de } \\
\text { aquênios. }\end{array}$
\end{tabular}

\section{CONCLUSÕES}

1. A altura de plantas, diâmetro de caule e número de folhas, para todos os genótipos avaliados, apresentaram-se dentro dos padrões estabelecidos para híbridos e variedades comerciais.

2. Os teores foliares de $\mathrm{N}, \mathrm{P}, \mathrm{Mg}, \mathrm{S}$ e B não foram influenciados pelos genótipos de girassol. Os teores foliares de $\mathrm{K}$ e $\mathrm{Ca}$ foram distintos entre os genótipos de girassol, sendo os maiores teores encontrados para os genótipos Helio 358 e MG341, respectivamente.

3. Os maiores rendimentos de grãos foram obtidos para os genótipos BRS G37, HLE 23, M734 e Helio 358.

4. Correlações positivas foram observadas entre os seguintes aspectos morfológicos: altura de plantas e diâmetro do caule, para Embrapa 122, M734, BRS G37 e BRS G41; altura de plantas e número de folhas, para Embrapa 122, HLE 23 e V90631; diâmetro de caule e número de folhas, para Embrapa 122 e V90631; teores de nutrientes e aspectos morfológicos para $\mathrm{N}$ e diâmetro de caule, para V90631; K e altura de plantas, para Embrapa 122; K e número de folhas, para Embrapa 122; e teores de nutrientes e rendimento de grãos, somente entre K e o genótipo M734.

\section{REFERÊNCIAS}

ABICHEQUER, A. D. Morfologia e distribuição de raizes de arroz irrigado por inundação e sua relação com a absorção de nutrientes e o rendimento de grãos. 2004. 66 f. Tese (Doutorado em Ciência do Solo) - Universidade Federal do Rio Grande do Sul, Porto Alegre, 2004.

AGUIAR NETO, P. et al. Efeitos da aplicação do fósforo no crescimento da cultura do girassol. Revista Verde de Agroecologia e Desenvolvimento Sustentável, Mossoró, v. 5, n. 4, p. 148-155, 2010.

ALVES, G. M. R. et al. Avaliação do crescimento de girassol no semiárido sob diferentes densidades de plantas. In: CONGRESSO BRASILEIRO DE MAMONA, 4., 2010, João Pessoa. Anais... Campina grande: Embrapa Algodão, 2010. p. 1181-1185.

AMABILE, R. F. et al. Teores de nutrientes em folhas de girassol (Helianthus annus L.) em distintas posições e estádios fenológicos. In: REUNIÃO NACIONAL DO GIRASSOL, 18., 2009, Pelotas. Anais... Pelotas: Embrapa Clima Temperado, 2009. p. $72-78$. 
AMORIM, E. P. et al. Correlações e análise de trilha em girassol. Bragantia, Campinas, v. 67, n. 2, p. 307-316, 2008.

AQUINO, L. A.; SILVA, F. D. B.; BERGER, P. G. Características agronômicas e o estado nutricional de cultivares de girassol irrigado. Revista Brasileira de Engenharia Agrícola e Ambiental, Campina Grande, v. 17, n. 5, p. 551-557, 2013.

BISCARO, G. A. et al. Adubação nitrogenada em cobertura no girassol irrigado nas condições de Cassilândia - MS. Ciência e Agrotecnologia, Lavras, v. 32, n. 5, p. 13661373, 2008.

BLAMEY, F. P. C.; EDWARDS, D. G.; ASHER, C. J. Nutritional disorders of sunflower. Brisbane: University of Queensland, 1987.

BORKERT, C. M. et al. Efeito residual da adubação potássica sobre girassol e milho em três diferentes Latossolos Roxos. Pesquisa Agropecuária Brasileira, Brasília, DF, v. 32, n. 12, p. 1227-1234, 1997.

BRASIL. Ministério da Agricultura, Pecuária e Abastecimento. Anuário estatístico de agroenergia 2012. Brasília, DF: MAPA/ACS, 2013.

CARVALHO, C. G. P. et al. Informes da avaliação de genótipos de girassol 2011/2012 e 2012. Londrina: Embrapa Soja, 2013. (Documentos, 340).

CARVALHO, C. G. P. et al. Genética do girassol. In: LEITE, R. M. V. B. C.; BRIGHENTI, A. M.; CASTRO, C. (Eds.). Girassol no Brasil. Londrina: Embrapa Soja, 2005. p. 219-267.

CASTRO, C.; FARIAS, J. R. B. Ecofisiologia do girassol. In: LEITE, R. M. V. B. C.; BRIGHENTI, A. M.; CASTRO, C. (Eds.). Girassol no Brasil. Londrina: Embrapa Soja, 2005. p. 163-218.

CASTRO, C.; OLIVEIRA, F. A. Nutrição e adubação do girassol. In: LEITE, R. M. V. B. C.; BRIGHENTI, A. M.; CASTRO, C. (Eds.). Girassol no Brasil. Londrina: Embrapa Soja, 2005. p. 317-373.

CASTRO, C. et al. Rochas brasileiras como fonte alternativa de potássio para a cultura de girassol. Espaço \& Geografia, Brasília, DF, v. 9, n. 2, p. 179-193, 2006.

CECÍlio FILHO, A. B.; GRANGeIRO, L. C. Produtividade da cultura da melancia em função de fontes e doses de potássio. Ciência e Agrotecnologia, Lavras, v. 28, n. 3, p. 561-569, 2004.

COMPANHIA NACIONAL DE ABASTECIMENTO (Conab). Acompanhamento da safra brasileira: $7^{\circ}$ levantamento, abril/2013. Brasília, DF: Conab, 2013.
EMPRESA BRASILEIRA DE PESQUISA AGROPECUÁRIA (Embrapa). Centro Nacional de Pesquisa de Solo. Manual de métodos de análise de solo. 2. ed. rev. atual. Rio de Janeiro: Embrapa, 1997. (Documentos, 1).

EMPRESA BRASILEIRA DE PESQUISA AGROPECUÁRIA (Embrapa). Centro Nacional de Pesquisa de Solos. Sistema brasileiro de classificação de solos. 2. ed. Rio de Janeiro: Embrapa-SPI, 2006.

FAGERIA, N. F. Otimização da eficiência nutricional na produção das culturas. Revista Brasileira de Engenharia Agricola e Ambiental, Campina Grande, v. 2, n. 1, p. 6-16, 1998.

FAGERIA, N. K. Solos tropicais e aspectos fisiológicos das culturas. Brasília, DF: Embrapa-CNPAF, 1989.

GUTTERRES, J. F. Disponibilidade de boro para as plantas em solos do Rio Grande do Sul. 1986. $145 \mathrm{f}$. Dissertação (Mestrado em Agronomia) - Faculdade de Agronomia, Universidade Federal do Rio Grande do Sul, Porto Alegre, 1986.

IVANOFF, M. E. A. Desempenho de cultivares de girassol em função do manejo da adubação nitrogenada e potássica em condições edafoclimáticas na savana de Boa Vista em Roraima. 2009. 54 f. Dissertação (Mestrado em Agronomia) - Universidade Federal de Roraima, Boa Vista, 2009.

JESUS, F. N. et al. Mudas de girassol submetidas a doses de potássio. Enciclopédia Biosfera, Goiânia, v. 9, n. 16, p. 1554-1565, 2013.

LEITE, R. M. V. B. C.; BRIGHENTI, A. M.; CASTRO, C. Girassol no Brasil. Londrina: Embrapa Soja, 2005.

MALAVOLTA, E.; VITTI, G. C.; OLIVEIRA, S. A. Avaliação do estado nutricional das plantas: princípios e aplicações. 2. ed. Piracicaba: Potafos, 1997.

OLIVEIRA, A. R. et al. Absorção de nutrientes e resposta à adubação em linhagens de tomateiro. Horticultura Brasileira, Brasília, DF, v. 27, n. 4, p. 498-504, 2009.

OLIVEIRA, F. A. et al. Interação entre salinidade e fontes de nitrogênio no desenvolvimento inicial da cultura do girassol. Revista Brasileira de Ciências Agrárias, Recife, v. 5, n. 4, p. 479-484, 2010.

OLIVEIRA, M. F.; CASTIGLIONI, V. B. R.; CARVALHO, C. G. P. Melhoramento do girassol. In: LEITE, R. M. V. B. C.; BRIGHENTI, A. M.; CASTRO, C. (Eds.). Girassol no Brasil. Londrina: Embrapa Soja, 2005. p. 268-297.

PRADO, R. M.; LEAL, R. M. Desordens nutricionais por deficiência em girassol var. catissol-01. Pesquisa Agropecuária Tropical, Goiânia, v. 36, n. 3, p. 187-193, 2006. 
SANTOS, J. F.; GRANGEIRO, J. I. T.; WANDERLEY, J. A. C. Comportamento produtivo do girassol em função de doses de nitrogênio. Revista Verde de Agroecologia e Desenvolvimento Sustentável, Mossoró, v. 8, n. 2, p. 4954, 2013.

SANZONOWICZ, C.; AMABILE, R. F. Adubação nitrogenada do girassol, no periodo chuvoso e na safrinha na região do Cerrado. Planaltina: Embrapa Cerrados, 2001.

SFREDO, G. J.; CAMPO, R. J.; SARRUGE, J. R. Girassol: nutrição mineral e adubação. Londrina: Embrapa-CNPSo, 1984. (Circular técnica, 8).

SOARES, M. R.; CASAGRANDE, J. C.; ALLEONI, L. R. F. Adsorção de boro em solos ácricos em função da variação do pH. Revista Brasileira de Ciência do Solo, Viçosa, v. 32, n. 1, p. 111-120, 2008.
SOUZA, D. M. G.; LOBATO, E. Cerrado: correção do solo e adubação. 2. ed. Brasília, DF: Embrapa Cerrados, 2004.

VILALBA, E. O. H. Recomendação de nitrogênio, fósforo e potássio para girassol sob sistema de plantio direto no Paraguai. 2008. 100 f. Dissertação (Mestrado em Ciência do Solo) - Universidade Federal de Santa Maria, Santa Maria, 2008.

ZOBIOLE, L. H. S. et al. Curva de crescimento, estado nutricional, teor de óleo e produtividade do girassol híbrido BRS 191 cultivado no Estado do Paraná. Revista Brasileira de Óleos e Fibrosos, Campina Grande, v. 14, n. 1, p. 55-62, 2010.

ZOBIOLE, L. H. S. et al. Sunflower micronutrient uptake curves. Ciência e Agrotecnologia, Lavras, v. 35, n. 2, p. 346-353, 2011. 